Martyna Paszkowska

\title{
„Poker face”, \\ czyli hiperboliczna (auto)kreacja, \\ czy kreacja hiperboli? - o twórczości Lady Gagi w dyskursie kultury popularnej
}

Lady Gaga - te dwa słowa to nie tylko pseudonim artystyczny dwudziestopięcioletniej Stefani Germanotty, ale i nazwa pewnego fenomenu, który można obserwować w kulturze popularnej od 2008 roku, kiedy to artystka wydała swoją pierwszą płytę The Fame. Warto zaznaczyć, iż do 2006 roku piosenkarka tworzyła muzykę pop w nieznanym dziś zespole Stefani Germanotta Band. Dopiero utwór Poker Face otworzył wokalistce drzwi do sławy. Tytuł okazał się znamienny - od samego początku kariery tożsamość piosenkarki płynnie się zmienia, ona zaś zachowuje „pokerową twarz”. Krytycy mody charakteryzują jej styl jako niesmaczny czy tandetny, fani dostrzegają świadomy zabieg postmodernistycznego pastiżu utrwalonych kulturowo kanonów wyglądu i zachowania gwiazd muzyki popularnej. Lady Gaga niewątpliwie należy do najbardziej rozpoznawalnych celebrytek, które bawią się muzycznymi i modowymi kanonami. Autokrytyczna twórczość wokalistki stanowi materiał do kulturowych badań nad płcią czy współczesną rolą (pop)feminizmu. Warstwę wizualną teledysków piosenkarki można łączyć z takimi kategoriami estetycznymi jak groteska, ironia czy camp ${ }^{1}$ co też spróbuję uczynić.

${ }^{1}$ Niektórzy znawcy tej kategorii estetycznej przypisują twórczość Lady Gagi do neokampu. Taka interpretacja jest możliwa ze względu na podział historyczny i swoiste wyczerpanie się campu, który opisywała Susan Sontag. 


\section{Seksualność i tożsamość}

W jednym z wywiadów Lady Gaga nazwała swoją muzykę „bezdusznym, elektronicznym popem"2 [Germanotta 2009] argumentując, iż apokalipsa już nastąpiła. Słowa te można rozumieć jako przewrotną autointerpretację twórczości, z pozoru niewyróżniającej się w warstwie muzycznej czy tekstowej niczym od innych piosenek muzyki tanecznej, która nierozerwalnie związana jest obecnie z wideoklipami. Analiza pierwszych teledysków artystki może prowadzić do prostych wniosków - oto na rynku muzycznym pojawiła się kolejna blond wokalistka, która stanowi gotowy produkt do kupienia. Wideoklipy zaprojektowane są przez producentów tak, by na płaszczyźnie wizualnej przestrzegana była nieśmiertelna triada „pieniądze - seks - przemoc”. Lady Gaga bezwstydnie demonstruje ciało, które służy jej jako narzędzie mające przyciągnąć uwagę odbiorcy przyzwyczajonego do oglądania na ekranie kobiecego negliżu. Jeden z czołowych badaczy seksualizacji kultury, autor pojęcia striptease culture (kultura obnażenia ${ }^{3}$ ) - Brian McNair zwraca uwagę na to, iż ciało ponowoczesne staje się medium komunikacji, której nadawcą jest sam człowiek. Zgodnie ze słowami Zygmunta Baumana „ciało jest przede wszystkim organem konsumpcji” [Opieczyńska 2011: 330]. Postępująca hedonizacja, która ma na celu ekstensyfikację przeżyć służy zaś estetyzacji rzeczywistości. Funkcjonujący w przeszłości etos „przezwyciężania ciała” na rzecz duchowej refleksji przekształcił się obecnie w prymat cielesności, poprzez którą postrzegana jest tożsamość jednostki. Współczesny człowiek buduje swoje „ja”, kultywując swoją zewnętrzność, a nie wewnętrzność.

Pojmowanie ciała jako narzędzia ekspresji tożsamości prowadzi do tego, iż podmiot traktowany jest jako dynamiczny i płynny układ stosunków. Tożsamość nie jest dana „od góry”, lecz ma charakter tym-

2 Wywiad został cytowany w wielu mediach.

3 Pojęcie opisywane szerzej w: McNair B. [2012], Streptease Culture, Sex: Media and the Democratization of Desire, Routledge, London. 
czasowy i potencjalny, co pozwala człowiekowi ją de-i rekonstruować. Zjawisko to potęguje rola mediów wytwarzających „narracyjne formy tożsamości do publicznego użytku poprzez »produkcję« zapośredniczonego doświadczenia, a więc nie »osobistego «, czerpanego z przekazów medialnych” [Melosik 2010: 164]. Mówi się o „tożsamości kinowej" [Bieńko 2010: 190], która na wzór patchworku łączy wiele wzorców osobowościowych reprezentantów kultury popularnej. Zjawisko to można łączyć z pojęciem kultury remiksu, które zostało wprowadzone przez Lawrence’a Lessiga. „Remiks bardzo dobrze wpisuje się w obszar kultury popularnej, w szerokim ujęciu może być także rozpatrywany przez pryzmat postmodernizmu” [Kuźmirz, Nożyński, 2012: 236]. W przypadku twórczości piosenkarki remiks jest nie tylko postmodernistycznym powtórzeniem i cytatem muzycznym, lecz również zapożyczeniem cech wielu muzycznych osobowości, czego dowodem jest już sam pseudonim nawiązujący do słynnego utworu Radio $\mathrm{GaGa}$ zespołu Queen.

Lady Gaga jest autorką wyrazistych, przerysowanych strojów, podobnie jak rekwizytorium, które nieodłącznie się z nią kojarzy. Zgodnie z Ervingiem Goffmanem zjawisko to można nazwać „fasadą osobistą" [Goffman 2005: 50]. Termin ten obejmuje środki wyrazu, które są ściśle związane z samym wykonawcą i niezmiennie towarzyszą mu. Artystka kojarzy się więc z barwnymi włosami, fantazyjnymi okularami i kostiumami własnego autorstwa lub też projektu modowych ikon takich jak Giorgio Armani czy Aleksander Macqueen. Piosenkarka na przemian zasłania i odsłania ciało, którym gra w sferze publicznej.

Analiza roli i sposobu demonstrowania przez wokalistkę cielesności nie może ominąć aspektu zmysłowości, który jest podkreślony w niemal każdym teledysku. Wydaje się jednak, że Lady Gaga jest artystką w pełni świadomą zjawiska dyskursywizacji seksualności w kulturze popularnej. W twórczości amerykańskiej piosenkarki widać bowiem ewolucję stylu. Z początku jej wizerunek nie odbiega od utrwalonego kanonu - teledyski utrzymane są w poetyce glamour. Lady Gadze towarzyszą rekwizyty typowe dla muzyki pop, a więc dyskotekowe okulary czy obcisłe, skąpe stroje, które prezentuje w prostych układach tanecznych na tle luksusowego basenu. Wideoklipy 
piosenkarki przedstawiają ją jako typową Power Girl - kobietę silną i świadomą swojej seksualności. Agresywny i mocno erotyzowany wizerunek, który wykorzystuje stylistykę porno chic jest dziś typowy dla kultury masowej przemysłu muzycznego. Pierwsze teledyski Lady Gagi wpisują się w nurt pop stripteaséu, który nie aspiruje do bycia niczym więcej jak zachęcającym i łatwo przystępnym dodatkiem do równie latwo przystępnych piosenek. Przełomowym obrazem wydaje się wideoklip do utworu Papparazzi, który stylizowany jest na film złotej ery Hollywoodu. Bohaterka krótkiej fabuły - gwiazda o tym samym pseudonimie artystycznym, co Lady Gaga, ulega wypadkowi, którego inicjatorem jest kochanek. Nagłówki gazet głoszą rychły koniec jej kariery, lecz oto kobieta powraca do swojej rezydencji. Taniec na wózku inwalidzkim oraz kulach nosi znamiona kampowości. Wyraziste i równie pomysłowe są same kostiumy artystki, które zasygnalizowały modowe prowokacje, do jakich z czasem doszło. Krótkie migawki scen ukazujące anonimowe kobiety w stanie agonalnym można interpretować jako symbol ofiary, którą składa niejeden celebryta walczący o sławę. Śmierć zostaje tu wyestetyzowana - zamiast płynącej krwi widzimy kałużę złota. Bohaterka dokonuje zemsty i morduje partnera, co tym samym przywraca jej popularność. Taki finał możemy odczytywać jako ironiczną krytykę środowiska muzyki pop, w którym zmagania o zdobycie czołowej pozycji na listach przebojów niekiedy dosłownie są walką o życie i śmierć. Ten metatekstowy charakter piosenki prowadzi do analizy sposobu bycia artystki w świecie popkultury. Działania Lady Gagi mieszczą się bowiem na granicy performance'u. Piosenkarka zasłynęła z pokazywania się publicznie $\mathrm{w}$ kuriozalnych nakryciach głowy takich jak kapelusz z brokatową imitacją homara, plastikowym telefonem na głowie czy puszkami od napojów wplecionymi we włosy, których kolor często się zmienia. Nie sposób nie wspomnieć $\mathrm{w}$ tym momencie o legendarnym już stroju z surowego mięsa, który jest jednoznacznie kojarzony z piosenkarką. Należy zaznaczyć, że pierwotnie pomysł ten zrealizowała Ann Simonton - modowa modelka lat siedemdziesiątych, która po tym jak została zgwałcona, stała się aktywną feministką. W latach osiemdziesiątych podczas protestów nosiła mięsne sukienki. 
Lady Gaga stała się ikoną mody haute couture, przerysowanych fryzur i niebotycznie wysokich butów. Z dziewczyny o ładnej buzi przeobraziła się w fame monstrum. Nazwa drugiej plyty wydaje się adekwatna - piosenkarka coraz częściej realizuje estetykę brzydoty. W teledysku Bad romance zamiast amerykańskiej dziewczyny widzimy więc bezpłciowego potwora, który wydostaje się z trumny. Obcisły, biały kostium zasłaniający niemal całą twarz powoduje, iż piosenkarka staje się zaprzeczeniem typowego ukazywania gwiazd pop. Jest antyprzykładem tego, co prezentują nastoletnie piosenkarki, których teledyski bazują przede wszystkim na erotycznych układach tanecznych.

$\mathrm{W}$ kolejnym wideoklipie - I was born this way - artystka również deformuje typowy wizerunek amerykańskiej wokalistki muzyki rozrywkowej. Intrygujący jest sam wstęp - na ekranie pojawia się różowy trójkąt - symbol homoseksualistów. Jego historia sięga drugiej wojny światowej. Oznaka o tym kolorze, którą Żydzi musieli umieścić na ubraniu była jednoznaczną śmiercią - odmienne upodobania seksualne traktowane były bowiem jako przestępstwo. W figurze tej zobaczyć można jednorożca, którego po chwili zastępuje obraz tajemniczych narodzin. Głos Lady Gagi z off-u komentuje poród Mother Monster, który dał początek nowej rasie ludzkiej cechującej się brakiem uprzedzeń i bezgraniczną wolnością. Wkrótce dochodzi do drugich narodzin - diabla. Zła matka przedstawiona jest w czerni i bieli, a jej wizerunek stanowi ukłon w stronę stylistyki twórcy Sin City - Franka Millera oraz kina noir. Wieczna Matka zostaje podzielona na dwie skrajne siły, które uzupełniają się nawzajem, co sugerują ostatnie słowa prologu: „How can I protect something so perfect without evil?" coś tak perfekcyjnego bez zła?

Dalsza część teledysku wydaje się być manifestem czy też apelem o akceptację samego siebie i wszelkiej inności. Lady Gaga występuje w samej bieliźnie. Z pozoru naturalny obraz jej ciała jest jednak wykrzywiony - widz z łatwością dostrzeże sześć guzów, które znajdują

${ }^{4}$ Wszystkie fragmenty cytowanych piosenek pochodzą z oficjalnej strony wokalistki: http://www.ladygaga.com/lyrics/default.aspx; [dostęp 27.10.2012]. 
się na czole, policzkach i ramionach wykonawczyni. Moda na zniekształcanie ciała wpisuje się w obecny trend inwazyjnej modyfikacji cielesności. Piercing, tatuaże, operacje plastyczne, które mają na celu upodobnienie do zwierząt lub odczłowieczenie wydają się odpowiedzią na pytania, które stawia posthumanizm. Charakterystyczną sceną, którą popkultura przejęła jest współczesny taniec śmierci, który Lady Gaga odgrywa wraz z Zombie Boy’em. Obraz wspólnego tańca stanowi nawiązanie do początkowych słów piosenki - diabeł, który utożsamia zło jest integralną częścią osobowości każdego człowieka. Na uwagę zasługuje także scena, w której artystka umieszczona jest na taśmie fabrycznej symbolizującej wielki inkubator, gdzie dojrzewają płody. Lady Gaga to jedno z wielu dzieci popkultury, co sama piosenkarka zdaje się podkreślać poprzez gesty takie jak taniec w białych rękawiczkach, który stanowi odwołanie do wizerunku Michaela Jacksona oraz moment, w którym płacze przed kamerą podobnie jak robiła to w swoim teledysku Madonna. Artystka wielokrotnie nawiązuje do starszej królowej popu, którą być może właśnie detronizuje. W teledysku Alejandro Lady Gaga bazuje na symbolach wykorzystywanych niejednokrotnie przez Madonnę. Krzyż w tle, krzyż na lateksowym płaszczu, strój zakonnicy, różaniec w ustach i grupa roznegliżowanych mężczyzn - na tym bazuje wideoklip. Początkowo mężczyźni posiadają typowo wojskowe atrybuty - czapki i ciężkie obuwie. Ich erotyczny taniec przypomina niemieckie zdjęcia Volku, gdzie podkreślano przede wszystkim męską tężyznę fizyczną i kult ciała. Ten obraz kontrastuje z scenami, kiedy to tancerze mają na sobie kabaretki i buty na obcasach. Co ciekawe podobną czarno - białą stylistykę przyjęła w najnowszym teledysku Girl gone wild sama Madonna tańcząca u boku mężczyzn ubranych jedynie w rajstopy i buty na obcasach.

Alejandro to wideoklip, który w bezpośredni sposób korzysta w chrześcijańskiej symboliki. Jawną interpretację biblijnych motywów znajdziemy także w wideoklipie Judas. Oto Lady Gaga przemienia się w świętą Magdalenę, która przytulona do ramion Jezusa wjeżdża do Nowego Jeruzalem z gangiem apostołów. Jej wzrok nieustannie szuka Judasza, który zgodnie z tekstem piosenki „(And Judas) is the demon I cling to, I cling to” - „jest demonem, do którego 
lgnę, do którego lgnę”. Gdy dochodzi do starcia między Judaszem a Jezusem w złotej koronie cierniowej, bohaterka z bólem celuje pistolem w twarz Chrystusowego zdrajcy - zamiast kuli wysuwa się jednak czerwona szminka, co jest zabiegiem wyjątkowo postmodernistycznym. „Detronizacja powagi” to jeden z wyznaczników campu, który w tym wypadku można rozumieć jako mrugnięcie oka w kierunku odbiorcy. Kolejna scena ma miejsce w wannie, gdzie kobieta obmywa obu mężczyznom stopy - walka miedzy dobrem a złem trwa nieustannie, chociaż można przypuszczać, że zła natura kobiety w ostatniej scenie ukamienowania zostaje zniszczona. Wideoklip może posłużyć jako przykład campu sakralnego - motywy maryjne takie jak niebieska szata, błyskotliwy naszyjnik- serce maryjne czy apostołowie - motocykliści, którzy mają skórzane kurtki ze swoimi imionami to gra $\mathrm{z}$ tradycyjnym wizerunkiem postaci biblijnych. Wydaje się jednak, że popkulturowe sięganie po motywy religijne w tym wypadku ma być czystą grą estetyczną czy metaforą walki dobra ze złem, nie zaś podważeniem wiary.

Na szczególną uwagę zasługuje konstrukcja teledysków. Niemal każdy z nich posiada filmowe wprowadzenie, przez co trwa dwa razy dłużej niż standardowy wideoklip muzyki pop. Zarówno w Born this way, jak i w Marry the Night sceny taneczne poprzedzone są długim monologiem, który ma charakter autobiograficzny. Wyjątkową estetykę można dostrzec również w teledysku You and I, gdzie piosenkarka została upodobniona do bohaterki filmu Terry'ego Gilliama - Kraina Traw. W tym samym klipie artystka występuje również jako mężczyzna. Tożsamość queer, którą przybiera Lady Gaga wydaje się być kolejnym krokiem w stronę dekonstrukcji utartych definicji kategorii płci. Wszystkie obrazy, które tworzy Gaga wydają się zaskakujące, niekiedy wręcz niesmaczne. Piosenkarka w przeciwieństwie do znanych gwiazd pop nie upiększa się, lecz staje się freakiem. Prowadzi to do prostego wniosku - w twórczości artystki zaakcentowana zostaje właśnie estetyka czy też antyestetyka. Teksty piosenek i brzmienia, które przypominają inne piosenki popowe nie są tak ważne jak teatralność, gra kulturowymi cytatami i przesadność, której oglądanie na ekranie niekoniecznie musi sprawiać 
odbiorcy przyjemność. Kategoria przyjemności jest zaś dla zjawiska kultury popularnej znamienna. Według Marka Krajewskiego - autora pozycji Kultury kultury popularnej paradoksalnie „popkulturowe przyjemności spełniają funkcję petryfikującą wobec porządku społecznego" [Krajewski 2003: 42]. Wynika z tego, że kultura popularna jest przestrzenią kontrolowaną, w której człowiek może wyrazić swoją odrębność, jednak tylko w taki sposób, by było to czytelne dla pozostałych uczestników kultury - przyjemności mimo pozorów zindywidualizowania są wspólne, dostępne dla wszystkich, ergo pozostają pod kontrolą" [Czernej, Nieroba, Szczepański 2010: 53]. Zgodnie z tym przedstawieniem można stwierdzić, iż Lady Gaga łamie zasady, którymi rządzi się popkultura.

\section{Kicz}

„Lady Gaga to królowa kiczu” - głoszą tabloidy. Artystka nieustannie zaskakuje barokowymi kreacjami, które prezentuje w niebotycznie wysokich butach i perukach. Znawcy śledzą jej modowe szaleństwa, dopatrując się w nich zarówno innowacyjnych rozwiązań, jak i kopiowania wzorców, które utrwaliła przez wieki historia mody. Czy styl piosenkarki rzeczywiście reprezentuje kategorię kiczu? Aby odpowiedzieć na to pytanie, należy wpierw zbadać status „estetyki szczęścia” ${ }^{5} \mathrm{w}$ dobie postmodernizmu. Kicz często przeciwstawiany jest sztuce, chociaż bez niej nie mógłby istnieć. Jak twierdzi Theodor Adorno, „w pojęciu sztuki implicite zawiera się kicz" [Adorno 1994: 219]. Takie stanowisko nie zyskało jednak na popularności - próbowano wyróżnić cechy tej kategorii, jak się okazało bezskutecznie. Kicz jako rezultat złego gustu, został więc eliminowany ze sztuki „prawdziwej”. Tymczasem ,jest pojęciem idiosynkratycznym: w tej samej mierze wiążącym, co niedającym się zdefiniować" [Kazimierska-Jerzyk 2000: 48]. Wydaje się, że brak rozróżnialności kopii od oryginału i odrzucenie tożsamości

${ }^{5}$ Pojęcie to nawiązuje do dzieła Moles A. [1978], Kicz, czyli sztuka szczęścia, PIW, Warszawa. 
uniemożliwia istnienie kiczu. Czy sztuka znajduje się na uprzywilejowanej pozycji skoro wszystko jest pozorem? Postmodernizm fascynuje się kiczem. Mnogość stylów, eklektyzm, fuzja kultur, tradycji oraz ekspresyjna dowolność to cechy charakterystyczne postmodernizmu, który jawnie powraca do motywów utrwalonej tandety. Powtórzenia wątków, cytaty cytatów, odnoszenie ich zarówno do innych tekstów, jak i metatekstowe komentarze powodują, że teksty kulturowe mieszają gatunki, style oraz dyskursy. To, co do niedawno było uznawane za kicz, z powrotem wraca do mody. Lady Gaga uznawana jest za wspólczesną gwiazdę popkultury, chociaż termin ten odnosi się do tego, co lubiane jest przez większość w określonym czasie. Lady Gaga nie jest zaś lubiana przez większość, ze względu na to, iż przewrotnie i często kontrowersyjnie ośmiesza wzory popkulturowe, do jakich należy między innymi współczesny ideał kobiecego piękna czy zmieniająca się nieustannie moda. Wielu odbiorców nie zna w pełni jej twórczości, lecz prawdopodobnie rozpoznaje artystkę. Z tego względu w Internecie znaleźć można memy komentujące nieustanne zmiany wizerunku piosenkarki, która upodabnia się do mężczyzny. Zabawne wydają się również realizację stricte popkulturowych lalek Barbie, które upodobnione są do artystki w najbardziej kuriozalnych strojach.

Lady Gaga wpisuje się w postmodernistyczną kulturę metamorfozy. Jej autokreacja jest świadoma i hiperboliczna. Szokuje, bulwersuje i zachwyca jednocześnie, lecz należy zastanowicie się do jakiego stopnia czerpie z istniejących już wzorców popkultury, a na ile tworzy ją sama. W wywiadach artystka wielokrotnie powtarza, iż całe jej życie jest teatrem.

Jakie jest więc przesłanie wokalistki? Czy jest to jedynie cyniczny komentarz odnośnie wyczerpania się popkultury? Czy za fasadą barokowej przesady i kryje się coś więcej niż upodobanie do estetyzowania wizerunku i afirmacja inności? Czy popularność piosenkarki przebrzmi czy też Lady Gaga zostanie ikoną - dziwadłem on the edge of glory? Nim przyjdzie odpowiedź na to pytania - w Internecie można znaleźć grę Lady Gaga Dress Up, która pozwala na indywidualną stylizację podobizny piosenkarki. W ten sposób każdy może stać się na chwilę Lady Gagą. 


\section{Bibliografia}

Adorno T. [1994], Teoria estetyczna, PWN, Warszawa.

Bieńko M. [2010], Sposoby postugiwania się tożsamością seksualna w kulturze popularnej, [w:] Kultura popularna konteksty teoretyczne i społeczno-kulturowe, Melosik A., Melosik Z. (red.) Oficyna Wydawnicza Impuls, Kraków.

Czerner A., Nieroba E., Szczepański M. [2010], Flirty tradycji z popkultura. Dziedzictwo kulturowe w później nowoczesności, Wydawnictwo Naukowe Scholar, Warszawa.

Goffman E. [2005], Człowiek $w$ teatrze życie codziennego, [w: ] Antropologia widowisk. Zagadnienia i wybór tekstów, Kolankowski L. (red.), Wydawnictwo Uniwersytetu, Warszawa.

Gromkowska-Melosik A. [2010], Power Girl i kontrowersje wokót wokót (pop) kulturowych emancypacji kobiet wspótczesnych, [w:] Kultura popularna konteksty teoretyczne i społeczno-kulturowe, Oficyna Wydawnicza Impuls, Kraków.

Kazimierska-Jerzyk W. [2000], Artysta postmodernistyczny - demaskator pozornych diagnoz kiczu, [w:] Kicz, tandeta, jarmarczność w kulturze masowej XX wieku, Rożek L. (red.), Wydawnictwo Naukowe WSP, Częstochowa.

Kuźmirz K., Nożyński Sz. [2012], Kultura remiksu a zmiany $w$ muzyce, [w:] Dyskursy kultury popularnej w społeczeństwie współczesnym, Oficyna Wydawnicza Impuls, Kraków.

Krajewski M. [2003], Kultury kultury popularnej, Wydawnictwo Naukowe UAM, Poznań.

Melosik Z. [2010], Ciało jako przedmiot studiów kulturowych, [w:] Kultura popularna konteksty teoretyczne i społeczno-kulturowe, Melosik A., Melosik Z. (red.) Oficyna Wydawnicza Impuls, Kraków.

Olszańska K., Roter A. [2010], Metamorfozy tożsamości jako skutek percepcji kultury makeover, [w:] Kultura popularna konteksty teoretyczne i spoteczno-kulturowe, Melosik A., Melosik Z. (red.) Oficyna Wydawnicza Impuls, Kraków.

Opieczyńska A. [2011], Porno chic, czyli seksualność jako narzędzie komunikacji, [w:] Kultura mediów, ciało i tożsamość - konteksty socjalizacyjne i edukacyjne, Jakubowski W., Jaskulska S. (red.), Oficyna Wydawnicza Impuls, Kraków. 
„Poker face”, czyli hiperboliczna (auto) kreacja...

\section{Wykaz stron internetowych}

http://www.allvoices.com/contributed-news/5400517-welcome-lady-gaga-the-mistress-of-death-to-the-postmodern; [dostęp 8.09.2012].

Oficjalna strona wokalistki: http://www.ladygaga.com/lyrics; [dostęp 27.10.2012].

Autor nieznany [2012], Tworzę bezduszny pop. Lady Gaga krytycznie o swojej muzyce, http://www.eska.pl/hotplota/news/tworze_bezduszny_ pop_lady_gaga/40090; [dostęp 27.10.2012]. 